\title{
Bone Age Determination of Epiphyseal Union Around Wrist Joint and its Correlation with Chronological Age: A Radiological Study in a Jordanian Population
}

\author{
Aiman Al-Qtaitat ${ }^{1 *}$, Jihad Alzyoud ${ }^{2}$, \\ Mohammad Al-Rawashdeh ${ }^{3}$, Said Al-Dalaen ${ }^{4}$ and Aiman Al-Maathadi ${ }^{1}$ \\ ${ }^{1}$ Department of Anatomy and Histology, Faculty of Medicine, Mutah University, Karak, Jordan. \\ ${ }^{2}$ Department of Medical Laboratory Sciences, Faculty of Allied Health Sciences, \\ Hashimite University, Zarqa, Jordan. \\ ${ }^{3}$ Department of Orthopaedic Surgery, Alkarak Governmental Hospital, Karak, Jordan. \\ ${ }^{4}$ Department of Pharmacology, Faculty of Medicine, Mutah University, Karak, Jordan. \\ http://dx.doi.org/10.13005/bbra/2004
}

(Received: 10 February 2016; accepted: 10 March 2016)

\begin{abstract}
Age determination is one of the most important parameters for human identification. Radiographic changes during epiphyseal union provide an important means to estimate the age of adolescent and young adult skeletons. This study aims to investigate the relationship between stage of epiphyseal union at the wrist joint and chronological age in a Jordanian population. The study was carried out in a total of 101 antero-posterior radiographs of healthy subjects (45 girls and 56 boys) aging from 12 to 22 years. The obtained results from the radiographs enrolled in the current study revealed that the complete union of lower end of radius is seen at 20-21 years. The complete union of lower end of ulna is seen at 20-21 years. Females were consistently developing epiphyseal union at a younger age than their male counterparts, with a two years difference. The results suggested that the ages of epiphyseal union are found to vary greatly all over the world indicating the need for separate standards of ages of epiphyseal union for separate regions.
\end{abstract}

Keywords: Epiphyseal union; Age estimation; Epiphysis; Ossification; Radius; Ulna; Bone age; Skeletal maturation; Wrist joint.

Today there is an increasing demand for age estimations in living individuals for both forensic and bioarchaeological contexts. The principal methods used for age determination are those of radiology, tooth morphology, and biochemistry. These methods differ widely with respect to potential, limits and risks ${ }^{1,2}$. Timing of epiphyseal union is an important means to estimate the age of adolescent and young adult skeletons. After puberty the process of growth in length of the long bones stops at different ages in different

\footnotetext{
* To whom all correspondence should be addressed. E-mail: aimanaq2000@yahoo.com
}

parts of different long bones, which is complete by the age of 22 years as described by various authors $^{3,4}$. It is clear that the timing of epiphyseal union is fairly constant with minor variations among different study groups of different geographic areas $^{5,6}$. The minor differences in the age of fusion could be due to effects of changes in climate, economic, hereditary, dietetic conditions ${ }^{7,8}$ or simply lack of standardized methodology. Furthermore, sexual variations in time of epiphysis maturation were well documented. In most of the studies females have shown earlier fusion as compared to their male counterparts ${ }^{9}$. Consequently, the need for separate standards of ossification for separate regions has been 
suggested $^{10,11,12}$. There are hundreds of ossification centers in the bones of the body. The long bones of upper and lower limbs play a vital role in assessment of age. The knee is an ideal anatomical locus for assessment of epiphyseal union, as the patient's knee joint often presents for investigation of trauma ${ }^{13}$. On the other hand, the hand-wrist region has received the greatest attention in assessment of skeletal maturation. The age for epiphyseal fusion of lower end of radius and ulna is bilaterally similar, i.e. it occurs at the same age in both hands, various studies have shown that the lower end (epiphysis) of radius and ulna fuses with their respective diaphysis within the age group of 16-20 years ${ }^{14,15,16}$. In the developing part of the world, and here in Jordan, a standard reference atlas for age estimation is in routine use. However, there is no available data concerning the completion of epiphyseal union among Jordanian population. So, the present study was carried out to investigate the ages of epiphyseal union around the wrist joint and its correlation with chronological age in modern Jordanian cohort.

\section{MATERIALSAND METHODS}

This retrospective cross-sectional analysis of the relationship between epiphyseal union at the wrist region and chronological age was undertaken using a sample of radiographs from Alkarak Governmental Hospital/South Jordan. A total of 107 healthy subjects having age from 12 to 22 years were enrolled in the present study. All the subjects belonged to middle socioeconomic status who have a history of residence in Alkarak/ South Jordan. Exclusion criteria were as follows: individuals who were not resident in Alkarak for less than 10 years, subjects who had musculoskeletal, nutritional and endocrine disorders and also without previous history of trauma or injury at the examined joints and bones, also very bad quality radiographs were excluded. The chronological age of each subject was calculated using information provided on the date of birth and the date of registration for the X-ray, therefore allowing the calculation of exact age in years at the time of the X-ray. The final number of subjects included in the study was 101 (56 boys and 45 girls). The subjects were subdivided into ten groups as follows: $12-13,13-14,14-15,15-16,16-17$, 17-18, 18-19, 19-20, 20-21, and 21-22 years according to their ages. The distribution of boys and girls in each age group is shown in Table 1. Anteroposterior view of wrist joint was examined in each case. All radiographs were evaluated by the physician who was informed only of the sex of the subject. The study was conducted according to the ethical forms approved by the Faculty of Medicine Ethics Committee in Mutah University.

\section{Criteria for union}

The different phases of epiphyses union will be graded into five stages according to McKern and Stewart (1957) ${ }^{17}$

(i) Non-union: When the epiphyseal cartilage does not begin to decrease in thickness ( 0 degree union),

(ii) Beginning union: When the thickness of the epiphyseal cartilages is reduced (1st degree union),

(iii) Incomplete union (Active union): When the epiphyses begins to fuse with the shaft (2nd degree union),

(iv) Recent union: When the epiphyseal cartilage is bony in architecture and its density indistinguishable from the epiphyses and diaphysis in its neighbourhood, but the epiphyseal scar is still distinguished (3rd degree union),

(v) Complete union with absence of epiphyseal scar (4th degree union).

\section{RESULTS}

The distribution of all subjects at each stage of union for the ten age groups is shown in Table 2. For both of the epiphyses (the lower end of both radius and ulna), the progression of epiphyseal closure through all stages of union is evident with increasing chronological age. It is to be remembered that for each age-group included in the study (e.g. 12-13 year), it represents the subjects who have completed a particular number of year (12 years) and not completed the next number of year (13 years).

\section{Lower end of radius}

Age group 12-13 years [6 cases (100\%)] were not showing even starting up of the process of epiphyseal fusion (Table 2). On advancing of age groups the process of epiphyseal fusion was seen to be advancing further and distributed 
between the different stages of union. It can be seen that in age groups 12-15 years there were no complete union. All age groups have one year interval. In this large time-span of one year wide changes can occur as far as epiphyseal fusion is considered. For example, in the age group 14-15 years, it can be noticed that 2 out of the 12 examined radius bones (16.67\%) were only showing the starting up of process of epiphyseal fusion (stage ii), 6 bones (50\%) were showing stage iii (incomplete union), while, recent union (stage iv) was noticed in the lower end of radius in the remaining 4 bones (33.33\%). On the other hand, the youngest age group showing complete union of lower end of radius was 15-16 years. The complete union of

Table 1. Age and sex distribution of all subjects

\begin{tabular}{lcccc}
\hline $\begin{array}{l}\text { Age Groups } \\
\text { (yrs) }\end{array}$ & Male & Female & Total & $\%$ \\
\hline $12-13$ & 3 & 3 & 6 & 5.94 \\
$13-14$ & 2 & 2 & 4 & 3.96 \\
$14-15$ & 7 & 5 & 12 & 11.88 \\
$15-16$ & 5 & 5 & 10 & 9.90 \\
$16-17$ & 6 & 5 & 11 & 10.89 \\
$17-18$ & 7 & 4 & 11 & 10.89 \\
$18-19$ & 6 & 7 & 13 & 12.87 \\
$19-20$ & 8 & 5 & 13 & 12.87 \\
$20-21$ & 6 & 5 & 11 & 10.89 \\
$21-22$ & 6 & 4 & 10 & 9.90 \\
Total & 56 & 45 & 101 & 100 \\
\hline
\end{tabular}

lower end of radius was seen in all cases at 20-21 years (Table 2). The distal end of radius showed complete union in 53 out of 101 cases examined (52.48\%) and those individuals distributed between the ages 15-22 years. Age groups 19-22 showed the majority of these unions presenting almost 33 out of 53 individuals (62.26\%).

\section{Lower end of ulna}

Age groups 12-15 showed no complete union of lower end of ulna; instead they were distributed between the different stages of union (Table 2). The youngest age group showing complete union of lower end of ulna is 15-16 years. The complete union of lower end of ulna was seen in all cases at 20-21 years. The distal end of ulna showed complete union in 51 out of the 101 examined individuals (50.50\%), and they were distributed between the ages 15-22 years. Age groups 19-22 show the majority of these unions presenting almost 32 out of 51 ulna bones (62.75\%). Comparing radius and ulna both showed the same youngest age group of complete union at their lower ends i.e. 15-16 years. Also, both showed complete union in all cases at the age group 20-21, whereas the remaining subjects were distributed in the different stages of union, as shown in Table 1.

\section{Males vs. females}

Tables 3 and Table 4 show the complete union in both sexes for the lower ends of radius and ulna, respectively. In the two tables as age

Table 2. The number of subjects at each stage of epiphyseal union in the lower ends of radius (R) and Ulna $(\mathrm{U})$ for each age group; $\mathrm{i}$ = Non-union, $\mathrm{ii}$ = Beginning union, iii = Incomplete union, $\mathrm{IV}=$ Recent union, $\mathrm{v}=$ Complete union

\begin{tabular}{|c|c|c|c|c|c|c|c|c|c|c|c|}
\hline \multirow{3}{*}{$\begin{array}{l}\text { Age Groups } \\
\text { (years) }\end{array}$} & \multicolumn{10}{|c|}{ Degree of Epiphyseal Fusion(Number Of Cases/ radius and ulna) } & \multirow[t]{3}{*}{ Total } \\
\hline & \multicolumn{2}{|c|}{ i } & \multicolumn{2}{|c|}{ ii } & \multicolumn{2}{|c|}{ iii } & \multicolumn{2}{|c|}{ iv } & \multicolumn{2}{|c|}{$\mathrm{v}$} & \\
\hline & $\mathrm{R}$ & $\mathrm{U}$ & $\mathrm{R}$ & $\mathrm{U}$ & $\mathrm{R}$ & $\mathrm{U}$ & $\mathrm{R}$ & $\mathrm{U}$ & $\mathrm{R}$ & $\mathrm{U}$ & \\
\hline $12-13$ & 6 & 5 & 0 & 1 & 0 & 0 & 0 & 0 & 0 & 0 & 12 \\
\hline $13-14$ & 1 & 1 & 2 & 2 & 1 & 1 & 0 & 0 & 0 & 0 & 8 \\
\hline $14-15$ & 0 & 0 & 2 & 3 & 6 & 6 & 4 & 3 & 0 & 0 & 24 \\
\hline $15-16$ & 0 & 0 & 0 & 0 & 4 & 3 & 4 & 5 & 2 & 2 & 20 \\
\hline $16-17$ & 0 & 0 & 0 & 0 & 3 & 4 & 5 & 4 & 3 & 3 & 22 \\
\hline $17-18$ & 0 & 0 & 0 & 0 & 1 & 1 & 4 & 5 & 6 & 5 & 22 \\
\hline 18-19 & 0 & 0 & 0 & 0 & 1 & 1 & 3 & 3 & 9 & 9 & 26 \\
\hline $19-20$ & 0 & 0 & 0 & 0 & 0 & 0 & 1 & 2 & 12 & 11 & 26 \\
\hline $20-21$ & 0 & 0 & 0 & 0 & 0 & 0 & 0 & 0 & 11 & 11 & 22 \\
\hline $21-22$ & 0 & 0 & 0 & 0 & 0 & 0 & 0 & 0 & 10 & 10 & 20 \\
\hline Total & 7 & 6 & 4 & 6 & 16 & 16 & 21 & 22 & 53 & 51 & 202 \\
\hline
\end{tabular}


groups advances, the numbers of cases showing complete union are proportionally increasing for females as compared to males. Complete union of lower end of radius was seen in $100 \%$ of the cases of age group 20-21 years in both sexes (Table 3). The complete union of lower end of radius was seen in $100 \%$ of males at $20-21$ years and in $100 \%$ of females at 18-19 years. Therefore, the age of union of lower end of radius is found to be 20-21 years for males and 18-19 years for females. The youngest age group showing complete union of radius epiphyses is $16-17$ years in males and 15-16 years females (Table 3). In case of lower end of ulna earliest age showing complete union in 100\% of the cases is 20-21 years and 18-19 years for males and females, respectively (Table 4). On the other hand, the earliest age group showing complete union is 17-18 years in case of males and 15-16 years in case of females (Table 4). Therefore, females showed earlier epiphyseal fusion at lower end of radius and ulna compared to males with a difference of two years.

\section{DISCUSSION}

The long bones of upper and lower limbs play a vital role in assessment of age both in living and dry remains. The study of the epiphyseal union

Table 3. The number of subjects showing complete union at the lower ends of radius for males and females for each age group

\begin{tabular}{lcccccc}
\hline $\begin{array}{l}\text { Age } \\
\text { Groups } \\
\text { (years) }\end{array}$ & \multicolumn{2}{c}{$\begin{array}{c}\text { Number of } \\
\text { che examined }\end{array}$} & \multicolumn{2}{c}{$\begin{array}{c}\text { Number of } \\
\text { Complete }\end{array}$} & \multicolumn{2}{c}{$\%$} \\
& M & F & M & F & M & F \\
\hline $12-13$ & 3 & 3 & 0 & 0 & 0 & 0 \\
$13-14$ & 2 & 2 & 0 & 0 & 0 & 0 \\
$14-15$ & 7 & 5 & 0 & 0 & 0 & 0 \\
$15-16$ & 5 & 5 & 0 & 2 & 0 & 40 \\
$16-17$ & 6 & 5 & 2 & 1 & 33.33 & 20 \\
$17-18$ & 7 & 4 & 3 & 3 & 42.86 & 75 \\
$18-19$ & 6 & 7 & 2 & 7 & 33.33 & 100 \\
$19-20$ & 8 & 5 & 7 & 5 & 87.50 & 100 \\
$20-21$ & 6 & 5 & 6 & 5 & 100 & 100 \\
$21-22$ & 6 & 4 & 6 & 4 & 100 & 100 \\
Total & 56 & 45 & 26 & 27 & & \\
\hline
\end{tabular}

of bones is considered a reasonable scientific and accepted method for the estimation of age by courts of law worldwide. The appearance and fusion of some ossification centers in the bones with others of the same bones form the basis of estimation of age. McKern and Stewart (1957) ${ }^{17}$ adopted a method that was based on dividing the process of epiphyseal union into five different stages. Currently there is an obvious lack of standards for epiphyseal union for the purposes of assignment of chronological age ${ }^{18}$. Therefore, interpretation is likely to vary among investigators within different countries; this may be explained, however, on the basis of how the authors have classified their range of union ${ }^{13}$. It is generally accepted that there was no difference in the stage of union of the various epiphyses between right and left sides, which indicates that epiphyseal union appears to occur at the same time on both sides $^{13,19}$. Thus, samples can be maximized in studies as authors do not need to select a particular side. Most of the studies in different geographical regions have performed a retrospective radiological method, which not only provide a mean for assessing the epiphyseal union but also offering the facility with which large numbers can be examined. Additionally, those retrospective studies have minimized health risks posed by

Table 4. The number of subjects showing complete union at the lower ends of ulna for males and females for each age group

\begin{tabular}{lcccccc}
\hline $\begin{array}{l}\text { Age } \\
\text { Groups } \\
\text { (years) }\end{array}$ & \multicolumn{2}{c}{$\begin{array}{c}\text { Number of } \\
\text { the examined }\end{array}$} & \multicolumn{2}{c}{$\begin{array}{c}\text { Number of } \\
\text { Complete }\end{array}$} & \multicolumn{2}{c}{$\%$} \\
& M & F & M & F & M & F \\
\hline $12-13$ & 3 & 3 & 0 & 0 & 0 & 0 \\
$13-14$ & 2 & 2 & 0 & 0 & 0 & 0 \\
$14-15$ & 7 & 5 & 0 & 0 & 0 & 0 \\
$15-16$ & 5 & 5 & 0 & 2 & 0 & 40 \\
$16-17$ & 6 & 5 & 0 & 3 & 0 & 60 \\
$17-18$ & 7 & 4 & 2 & 3 & 28.57 & 75 \\
$18-19$ & 6 & 7 & 2 & 7 & 33.33 & 100 \\
$19-20$ & 8 & 5 & 6 & 5 & 75 & 100 \\
$20-21$ & 6 & 5 & 6 & 5 & 100 & 100 \\
$21-22$ & 6 & 4 & 6 & 4 & 100 & 100 \\
Total & 56 & 45 & 22 & 29 & & \\
\hline
\end{tabular}


repeated radiological examinations which are not ethically possible. Here in Jordan skeletal age determination is usually performed by comparing the plain radiograph of a patient with findings in a normal reference of other populations. No radiographic study of the epiphyseal union has previously carried out in Jordan. This retrospective study is the first assessment of epiphyseal union at the wrist joint to be undertaken in a Jordanian population.

Various studies have shown that the lower end of radius and ulna fuse with their respective diaphysis between the age of 15 and 21 years (Table 5). The results in the present study showed that the complete fusion of distal ends of both radius and ulna among the people of Jordan is taking place between the age of 18 and 21 years. As illustrated in Table 5, some studies of other authors' showed variability from our results. Other authors are having conclusions parallel with our study. Davis and Parsons (1927) ${ }^{30}$ and Paterson $(1929)^{20}$, in their early studies on the population of Great Britain have described that the epiphyseal union at lower end of radius and ulna occurs in the same age group, which is in agreement with our obtained results. Thus, populations of Jordan and England have same age for epiphyseal union as far as lower end of radius and ulna are concerned. On the other hand, among Jordanians there was no difference between the ages of epiphyseal union between the lower ends of radius and the lower end of ulna. Conversely, many workers from different regions have reported that fusion at lower end of ulna shows epiphyseal union in advance of the lower end of radius with a difference of less than a year (Table 5). Variations between authors have been recorded not only by workers from different countries but even by the workers from various states of a large country such as India ${ }^{28}$. Those countable differences in the appearance and fusion activities of ossification centers are depending on race geographic distribution and sex. The process of ossification may also be influenced by food habit, nutritional status, infectious diseases, hormonal and metabolic disorders and physical activity ${ }^{31}$. So, this suggests that the correct criteria should be used in age estimation for separate regions.

The current study found that females are consistently developing epiphyseal union at a younger age than their male counterparts. In their early studies, Pryor $(1925,1933)^{22,32}$, Greulich and Pyle (1959) ${ }^{14}$ and Loomba (1958) ${ }^{33}$ have stressed that the bones of females ossify in advance of male. Majority of the authors reported conclusions parallel with the results in our study (Table 5). This study has noted that there is generally a difference of two years between males and females, which is in agreement with the results of previously published studies, which have found that females typically develop union approximately two years in advance of males ${ }^{16,20,24,25,34,35}$. Therefore, it is

Table 5. Comparison of ages of epiphyseal union of distal ends of radius and ulna between other workers and the present study

\begin{tabular}{|c|c|c|c|c|c|}
\hline \multirow{3}{*}{ Author/ year } & \multirow{3}{*}{ Subjects } & \multicolumn{4}{|c|}{ Complete union/ years } \\
\hline & & \multicolumn{2}{|c|}{ Radius } & \multicolumn{2}{|c|}{ Ulna } \\
\hline & & Females & Males & Females & Males \\
\hline Paterson (1929) [20] & English & $19-20$ & 21 & $19-20$ & 21 \\
\hline Sidhom and Derry (1931) [21] & Egyptians & - & $19-20$ & - & $19-20$ \\
\hline Pryor (1933) [22] & American & 20 & 19 & 18 & 19 \\
\hline Galstaun (1937) [23] & Bengalis/ Indian & 16 & 18 & 17 & 18.5 \\
\hline Flecker (1942) [24] & Australians & 18 & 19 & 17 & 19 \\
\hline Greulich and Pyle (1959) [14] & American & 17 & Above 18 & 18 & 19 \\
\hline Hansman (1962) [25] & Americans & 16 & 18 & 16 & 18 \\
\hline Rikhasor and Qureshi (1994) [26] & Pakistanis & 16 & 18 & 15.5 & 17.5 \\
\hline Sahni and Jit (1995) [27] & Punjabis & Above 16 & - & Above 16 & - \\
\hline Nemade et al (2010) [28] & Vidarbha & $19-20$ & $20-21$ & $19-20$ & $19-20$ \\
\hline Memon et al (2012) [29] & Pakistanis & $15-16$ & $16-17$ & $15-16$ & $16-17$ \\
\hline Present study (2015) & Jordanian & $18-19$ & $20-21$ & $18-19$ & $20-21$ \\
\hline
\end{tabular}


clear that separate age range standards are required for males and females to ensure the greatest accuracy of age estimation ${ }^{13}$.

\section{CONCLUSION}

The current study is the first to present a radiographic technique, which assists the process of epiphyseal union at the wrist joint among Jordanian population. The completion of epiphyseal union in Jordanian population for the lower end of both radius and ulna is at the age of 20-21 and 18-19 years for males and females, respectively. The ages of epiphyseal union are found to vary greatly all over the world indicating the need for separate standards of ages of epiphyseal union for separate regions. It is recommended to collect data for more subjects and from different parts of the country in future studies, which will supplement the information yielded by the current study. Also, it is intended to combine information from as many epiphyses as possible to provide the most accurate estimate of epiphyseal union for the purposes of assignment of chronological age.

\section{REFERENCES}

1. Ubelacker DH. Estimating age at death from immature human skeletons: an overview. $J$ Forensic Sci 1987; 32: 1254-1263

2. Ritz S, Kaatsch HJ. Methoden der Altersbestimmung an lebenden Personen: Möglichkeiten, Grenzen, Zulässigkeit und ethische Vertretbarkeit. Rechtsmedizin 1996; 6:171-176

3. Stevenson PH. Age order of epiphyseal union in man. Am J Phys Anthropol 1924; 7: 53-93.

4. Ubelaker DH. The estimation of age at death from immature human bone. In Age Markers in the Human Skeleton (ed. Isçan MY). Springfield, IL: Charles C Thomas, 1989.

5. Banerjee KK and Agarwal BBL. Estimation of age from epiphyseal union at the wrist and ankle joints in the capital city of India. Forensic Sci Int 1998; 98: 31-39.

6. Schaefer MC and Black SM. Comparison of ages of epiphyseal union in North American and Bosnian skeletal material. J Forensic Sci 2005; 50: 777-784.

7. Eveleth P and Tanner JM. Worldwide Variation in Human Growth, 2nd edn. Cambridge:
Cambridge University Press1990.

8. Lampl $\mathbf{M}$ and Johnston FE. Problems in the aging of skeletal juveniles: perspectives from maturation assessments of living children. Am J Phys Anthropol 1996; 101: 345-355.

9. Kreitner KF, Schweden FJ, Riepert T, Nafe B and Thelen $\mathrm{M}$. Bone age determination based on the study of the medial extremity of the clavicle. Eur. Radiol. 1998; 8: 1116-1122.

10. Loder RT, Estle DT, Morrison K, Eggleston D, Fish DN, Greenfield ML and Guire KE. Applicability of the Greulich and Pyle skeletal age standards to black and white children of today. Am. J Dis. Child 1993; 147(12): 13291333.

11. Koc A, Karaoglanoglu M, Erdogan M, Kosecik $\mathrm{M}$ and Cesur Y. Assessment of bone ages: is the Greulich- Pyle method sufficient for Turkish boys? Pediatr. Int 2001; 43(6): 662-665

12. Crowder $C$ and Austin D. Age ranges of epiphyseal fusion in the distal tibia and fibula of contemporary males and females. J. Forensic Sci 2005; 50(5): 1001-1007.

13. O’Connor JE, Bogue C, Spence LD and Last J. A method to establish the relationship between chronological age and stage of union from radiographic assessment of epiphyseal fusion at the knee: an Irish population study. J. Anat. 2008; 212: 198-209.

14. Greulich WW and Pyle SI. Radiographic Atlas of Skeletal Development of the Hand and Wrist. Stanford, CA: Stanford University Press 1959.

15. Lee MMC. Problems in combining skeletal age for an individual. Am J Phys Anthropol 1971; 35: 395-398.

16. Dharmesh S. Patel, Harish Agarwal and Jigesh V. Shah. Epiphyseal Fusion at Lower End of Radius and Ulna Valuable Tool for Age Determination. J Indian Acad Forensic Med. 2011; 33(2): 125-129.

17. McKern TW and Stewart TD. Skeletal age changes in young American male. The United States of America Army Quartermaster Research and Development Command, Technical Report EP-45, Natick, Massachusetts 1957.

18. Bokariya P, Chowdhary DS, Tirpude BH, Kothari R and Waghmare JE. A Review of the Chronology of Epiphyseal Union in the Bones at Knee and Ankle Joint. J Indian Acad Forensic Med. 2011; 33(3): 258-260

19. Albert AM and Greene DL. Bilateral asymmetry in skeletal growth and maturation as an indicator of environmental stress. Am J Phys Anthropol 1999; 110: 341-349.

20. Paterson RS. A radiological investigation of the epiphyses of long bones. TA Anat 1929; 64:28- 
46

21. Sidhom G and Derry DE. Dates of union of some epiphyses in Egyptian from X-ray photographs. J. Anat 1931; 65: 196211.

22. Pryor JW. Time of ossification of the bones of the hand of male and female and union of epiphyses with diaphysis. American Journal of Physical Anthropology 1933; 8: 401-410.

23. Galstaun GA. A study of ossification as observed in Indian subjects. J Med Res 1937; 25:267-327.

24. Flecker H. Time of appearance and fusion of ossification centers as observed by Roentgenographic methods. American Journal of Roentgenology 1942; 47: 97-159.

25. Hansman CF. Appearance and fusion of ossification centers in the human's skeleton. Am J Radiol 1962; 88 :476-82.

26. Rikhasor M, Qurashi AH. Determination of age in children from 1-7 years. Pak J Med 1994; 15:38-40.

27. Sahni D and Jit I. Time of fusion of epiphyses at the elbow and wrist joints in girls of northwest India. Forensic Science Internation.1995; 74(12): 47-55.

28. Nemade KS, Kamdi NY and Parchand MP. Ages of Epiphyseal Union Around Wrist Jiont - A Radiological Study. J. Anat. Soc. India 2010;
59(2): 205-210.

29. Memon N, Memon MU, Memon K, Junejo H and Memon J. Radiological Indicators for Determination of Age of Consent and Criminal Responsibility. JLUMHS 2012; 11(2): 64-70

30. Davies DA, Parsons FG. The age order of the appearance and union of the normal epiphysis as seen by X ray. J Anat. 1927; 62: 58-71.

31. Pradeep Bokariya, Chowdhary DS, Tirpude BH, Ruchi Kothari, Waghmare JE and Aaditya Tarnekar. A Review of the Chronology of Epiphyseal Union in the Bones at Knee and Ankle Joint. J Indian Acad Forensic Med. 2011; 33(3):258-260.

32. Pryor JW. Time of ossification of the bones of the hand of male and female and union of epiphyses with diaphyses, American Journal of Physical Anthropology. 1925; 8(4): 401-410.

33. Loomba SD. Age of epiphyseal union at wrist joint in Uttar Pradesh. Journal of Ind Med Association. 1958; 30(12): 389-395. 7.

34. Narayan D and Bajaj ID. Ages of epiphyseal union in long bonesof inferior extremity in U.P. subjects. Indian J Med Res 1957; 45: 645- 649.

35. Saksena JS and Vyas SK. Epiphyseal union at the wrist, knee and iliac crest in residents of Madhya Pradesh. J Indian Med Assoc 1969; 55: 67-68. 